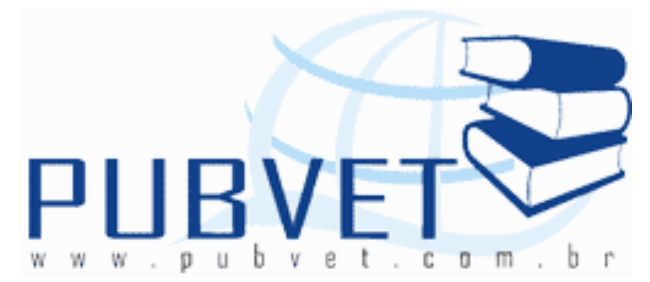

PUBVET, Publicações em Medicina Veterinária e Zootecnia.

\title{
Pesquisa de amastigotas de Leishmania spp. em linfonodos, medula óssea, baço, pele e sangue de cães naturalmente infectados
}

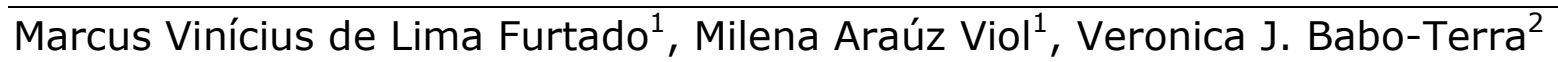

1 Médico(a) Veterinário(a)

2 Prof. Dra. Clínica Méd. e Terap. de Pequenos Animais UFMS, DMV; e-mail: vjb@terra.com.br

\section{Resumo}

A Leishmaniose Visceral é uma antropozoonose que resulta do parasitismo dos hospedeiros vertebrados por protozoários do gênero Leishmania, transmitida por insetos hematófagos pertencentes ao gênero Lutzomyia. Os cães são considerados os principais reservatórios do parasita, sendo importantes para a manutenção do ciclo da doença. Nos últimos anos, a doença vem se disseminando por muitas regiões do Brasil, com uma crescente e preocupante prevalência em Mato Grosso do Sul, principalmente em Campo Grande. O diagnóstico da Leishmaniose canina deve ser feito com base nos sinais clínicos, na visualização do parasita em materiais de biopsia de linfonodos e medula óssea, em exames sorológicos como a Reação de Imunofluorescência Indireta (RIFI), ELISA, métodos moleculares como a Reação da Polimerase em Cadeia (PCR) ou ainda por cultivo. O objetivo desse trabalho foi avaliar a presença de

formas amastigotas de Leishmania spp. em materiais obtidos por punção de linfonodos, medula óssea, baço, sangue periférico e pele, de cães 
FURTADO, M.V.L., VIOL, M.A. e BABO-TERRA, V.J. Pesquisa de amastigotas de Leishmania spp. em linfonodos, medula óssea, baço, pele e sangue de cães naturalmente infectados. PUBVET, Londrina, V. 5, N. 30, Ed. 177, Art. 1198, 2011.

sorologicamente positivos para os testes de ELISA e Imunofluorescência indireta. Entre os 32 animais estudados, a presença de formas amastigotas de Leishmania spp. foi observada em todos os órgãos em 24 cães. Foi verificada também a presença de mórulas sugestivas de Ehrlichia canis em 12 animais, sendo que 4 destes cães foram parasitologicamente negativos para Leishmania spp., reforçando a necessidade de métodos diagnósticos mais eficazes para a confirmação da leishmaniose canina.

Palavras-chave: Leishmaniose visceral; diagnóstico; cães; erliquiose

\section{Leishmania spp. amastigotes in lymph nodes, bone marrow, spleen, skin and blood of naturally infected dogs}

\section{Summary}

Visceral leishmaniasis is an anthropozoonosis caused by the protozoa of the genus Leishmania and is transmitted by sandflies of the genus Lutzomyia. Dogs are considered the major reservoirs of parasite, being important for the maintence of the cycle of the disease. In recent years, the disease has been spreading throughout many regions of Brazil, with a growing and worrying prevalence in Mato Grosso do Sul, mainly in Campo Grande. The diagnosis of canine leishmaniasis should be done based on clinical signs, visualization of the parasite in biopsy samples from bone marrow and lymph nodes, serologic tests such as indirect immunofluorescence (IFA), ELISA, molecular methods such as Polymerase Chain Reaction (PCR) or even tissue culture. The purpose of this work was to observe the presence of amastigote forms of Leishmania spp. In samples obtained through biopsy of lymph nodes, bone marrow, spleen, peripheral blood and skin from ELISA and IFA positive dogs. Among the 32 animals studied, the presence of Leishmania forms was observed in all studied tissues of 32 dogs. It was also verified the presence of inclusions suggestive of Ehrlichia canis in 12 dogs, from witch 4 dos were negative for Leishmania spp. In cytological examinations, reinforcing the need for better confirming methods for canine leishmaniasis.

Keywords: Canine Leishmaniasis; diagnosis; dogs, ehrlichiosis 
FURTADO, M.V.L., VIOL, M.A. e BABO-TERRA, V.J. Pesquisa de amastigotas de Leishmania spp. em linfonodos, medula óssea, baço, pele e sangue de cães naturalmente infectados.

PUBVET, Londrina, V. 5, N. 30, Ed. 177, Art. 1198, 2011.

\section{Introdução}

A leishmaniose visceral canina (LVC) é uma antropozoonose causada por um protozoário flagelado, do gênero Leishmania, pertencente ao complexo donovani, que compreende a Leishmania infantum, Leishmania donovani e Leishmania chagasi, esta última encontrada no Brasil (Genaro 1993, Ribeiro 1997, Santa Rosa \& Oliveira 1997). A doença é endêmica na América, Europa e países asiáticos (Pearson \& Sousa 1996, Herwaldt 1999) e novas áreas de infecção ainda estão sendo identificadas (Enserink 2000, Silva et al. 2001).

Nos últimos dez anos, a leishmaniose visceral vem passando por um processo de urbanização, aspecto esse que deve ser considerado na epidemiologia da doença. A endemia vem passando de doença quase que exclusiva de áreas rurais para uma distribuição maior em áreas urbanas. Exemplos deste fenômeno de expansão-urbanização são surtos epidêmicos em diversos estados do Brasil (Passos 1993, Marzochi 1994, Santa Rosa \& Oliveira 1997).

Os vetores implicados na transmissão das leishmanioses são insetos denominados flebotomíneos conhecidos popularmente como mosquito palha, birigüis ou tatuquiras, e consistem de várias espécies do gênero Lutzomyia, sendo a principal a Lu. longipalpis. Estes dípteros veiculam as formas promastigotas do parasito dos animais infectados para os animais susceptíveis ou para o homem (Feitosa et al. 2000, Brasil 2003). Durante o repasto sangüíneo, a fêmea do flebotomíneo ingere macrófagos parasitados por leishmanias que, do intestino do mosquito seguem o ciclo necessário para o seu desenvolvimento (Fortes 1997). As leishmanias também podem ser transmitidas por meio de transfusão sanguínea e acidentes de laboratório (Cabral et al. 1992).

O cão é considerado o reservatório da doença e como hospedeiro, apresenta variações no quadro clinico da doença variando de animais aparentemente sadios a oligossintomáticos, podendo chegar a estágios graves da doença, com intenso parasitismo cutâneo (Abranches et al. 1991).

Os principais sinais clínicos observados são onicogrifose (Ciaramella et al. 1997, Koutinas et al. 1999), linfadenomegalia, emagrecimento progressivo, 
FURTADO, M.V.L., VIOL, M.A. e BABO-TERRA, V.J. Pesquisa de amastigotas de Leishmania spp. em linfonodos, medula óssea, baço, pele e sangue de cães naturalmente infectados.

PUBVET, Londrina, V. 5, N. 30, Ed. 177, Art. 1198, 2011.

febre, anemia, nefrite auto-imune com alterações na função renal (Kontos et al. 1993, Blavier et al. 2001), hepatoesplenomegalia, poliartrite e lesões oculares como conjuntivite, edema de córnea e úlcera de córnea. Também são observados sinais neurológicos por encefalites, meningites e mielites (Yamaguchi et al. 1983).

Por ser uma doença de notificação compulsória, o diagnóstico da leishmaniose visceral deve ser feito de forma mais precisa possível e para isso é importante que se conheça o método utilizado, suas limitações e sua interpretação clínica (Ferrer et al. 1999, Brasil 2003).

Os teste sorológicos incluem fixação de complemento, hemaglutinaçao indireta, aglutinação em látex, aglutinação direta, imunoeletroforese, imunofluorescência indireta, ELISA, imunoprecipitação em gel e Western blot (Scalone et al. 2002). Entretanto, os testes sorológicos devem ser interpretados com cautela, uma vez que não são cem por cento sensíveis (Ferrer et al. 1995, Leontides et al. 2002).

O diagnóstico parasitológico é $o$ método definitivo e se baseia na demonstração do parasito. Este pode ser encontrado principalmente nos órgãos linfóides, medula óssea e pele. No entanto, em alguns casos é impossível a detecção do parasito mesmo em animais infectados (Ferrer 1992). A sensibilidade do teste depende do grau de parasitemia, do tipo de material biológico coletado, da experiência do examinador e do tempo de leitura da lâmina, podendo atingir no máximo $80 \%$ em cães sintomáticos e uma porcentagem menor em cães assintomáticos (Brasil 2003).

Dentre os métodos moleculares, o da reação da polimerase em cadeia (PCR) permite identificar e ampliar seletivamente a seqüência de DNA do parasita, com sensibilidade de oitenta e oito por cento logo após a infecção, mas esta declina ate cinqüenta por cento nos meses subseqüentes (Slappendel et al.1990, Noli 1999, Quinnell et al. 2001, Ferrer 2002).

O seguinte trabalho teve como objetivo avaliar a presença de formas amastigotas de Leishmania spp. em materiais obtidos por punção de linfonodos, medula óssea, baço, sangue periférico e pele, de cães 
FURTADO, M.V.L., VIOL, M.A. e BABO-TERRA, V.J. Pesquisa de amastigotas de Leishmania spp. em linfonodos, medula óssea, baço, pele e sangue de cães naturalmente infectados. PUBVET, Londrina, V. 5, N. 30, Ed. 177, Art. 1198, 2011.

sorologicamente positivos para os testes de ELISA e RIFI, apreendidos pelo Centro de Controle de Zoonoses (CCZ) do município de Campo Grande - MS.

\section{Materiais e Métodos}

No estudo foram utilizados 32 cães com idade média de 3.5 anos, sendo 15 machos e 17 fêmeas, todos sorologicamente positivos para o teste de ELISA e posteriormente para o RIFI (cut-off 1:40), realizados no Centro de Controle de Zoonoses (CCZ), localizado no município de Campo Grande, Estado de Mato Grosso do Sul.

O material foi coletado no centro cirúrgico das dependências do $C C Z$, com os animais previamente anestesiados com Tiopental sódico $1 \mathrm{~g}$ (Thiopentax ${ }^{1}{ }^{1}$ ), na diluição de 2,5\%, utilizando-se a dose de $25 \mathrm{mg} / \mathrm{kg}$ por via endovenosa, certificando-se previamente de que 0 animal atingira o plano anestésico profundo por meio de auscultação cardíaca e teste de sensibilidade cutânea.

Na punção aspirativa dos linfonodos pré-escapular e poplíteo foram utilizadas seringas descartáveis de $3 \mathrm{ml}$ e agulha 22G 1 (25×07). A punção de medula óssea foi efetuada na junção tíbio-femural e na crista ilíaca com seringas descartáveis de $20 \mathrm{ml}$ contendo $1 \mathrm{ml}$ de anticoagulante (EDTA) e agulha 18G $1 \frac{1}{2}(12 \times 40)$. O sangue foi coletado da veia cefálica com seringa descartável de $5 \mathrm{ml}$ e agulha 22G 1 (25x07). Para a punção do baço utilizou-se seringa descartável de $5 \mathrm{ml}$ contendo 0,5 $\mathrm{ml}$ de EDTA e agulha 21G 1 (25×08). Para as amostras de pele foi feito imprint de ponta de orelha. As lâminas contendo o material coletado foram fixadas com metanol, coradas pelo método de Giemsa e analisadas ao microscópio óptico sob imersão, com objetiva de 100x.

\section{Resultados}

Entre os 32 animais sorologicamente positivos que foram submetidos à coleta de material para análise parasitológica, a presença de formas amastigotas de Leishmania spp. foi observada em todos os órgãos, listados na forma

\footnotetext{
${ }^{1}$ Thiopentax $\AA$ - $1 \mathrm{~g}$ - Cristália
} 
FURTADO, M.V.L., VIOL, M.A. e BABO-TERRA, V.J. Pesquisa de amastigotas de Leishmania spp. em linfonodos, medula óssea, baço, pele e sangue de cães naturalmente infectados. PUBVET, Londrina, V. 5, N. 30, Ed. 177, Art. 1198, 2011.

decrescente de incidência: medula óssea - crista ilíaca (50\%); medula óssea tíbio-femural $(46,87 \%)$; baço $(40,62 \%)$; linfonodo pré-escapular $(37,5 \%)$; linfonodo poplíteo $(37,5 \%)$; pele $(25 \%)$; sangue periférico $(3,12 \%)$ (Figura 1$)$. Oito destes animais não apresentaram o parasita em nenhum dos órgãos analisados.

Foi verificada também a presença de mórulas sugestivas de Ehrlichia canis em 12 animais, sendo que 4 em cães parasitologicamente negativos para Leishmania spp. e 8 em cães positivos.

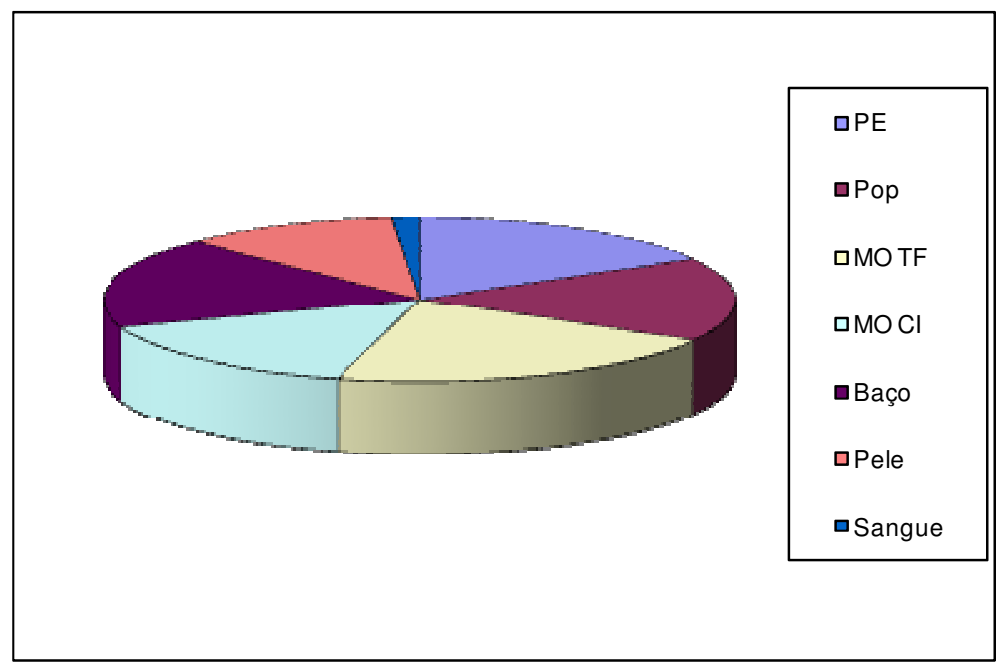

Figura 1. Presença de amastigotas de Leishmania spp. nos diversos tecidos

Tabela 1. Deteç̧ão de amastigotas de Leishmania spp. nas amostras de cães naturalmente infectados

$\begin{array}{lccccc} & \text { Macho }(+) & \text { Macho }(-) & \text { Fêmea }(+) & \text { Fêmea }(-) & \text { Total }(+) \\ \text { Linfonodo pré-escapular } & 6 & 9 & 6 & 11 & 12 \\ \text { Linfonodo poplíteo } & 6 & 9 & 6 & 11 & 12 \\ \text { Medula óssea tíbio-femural } & 6 & 9 & 9 & 8 & 15 \\ \text { Medula óssea crista-ilíaca } & 5 & 10 & 6 & 11 & 11 \\ \text { Baço } & 6 & 9 & 7 & 10 & 13 \\ \text { Pele } & 3 & 12 & 5 & 12 & 8 \\ \text { Sangue periférico } & 1 & 14 & 0 & 17 & 1\end{array}$


FURTADO, M.V.L., VIOL, M.A. e BABO-TERRA, V.J. Pesquisa de amastigotas de Leishmania spp. em linfonodos, medula óssea, baço, pele e sangue de cães naturalmente infectados. PUBVET, Londrina, V. 5, N. 30, Ed. 177, Art. 1198, 2011.

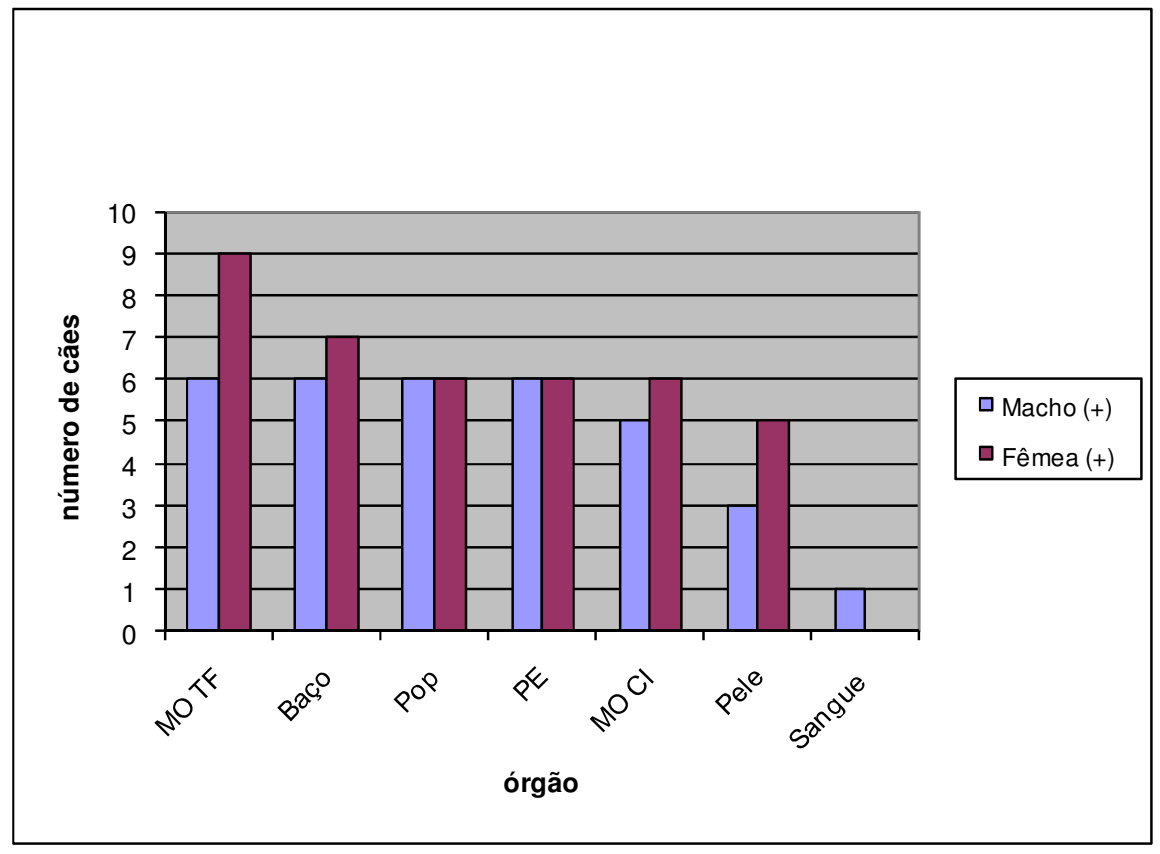

Figura 2. Proporção de animais com amastigotas de Leishmania spp. distribuídos por sexo

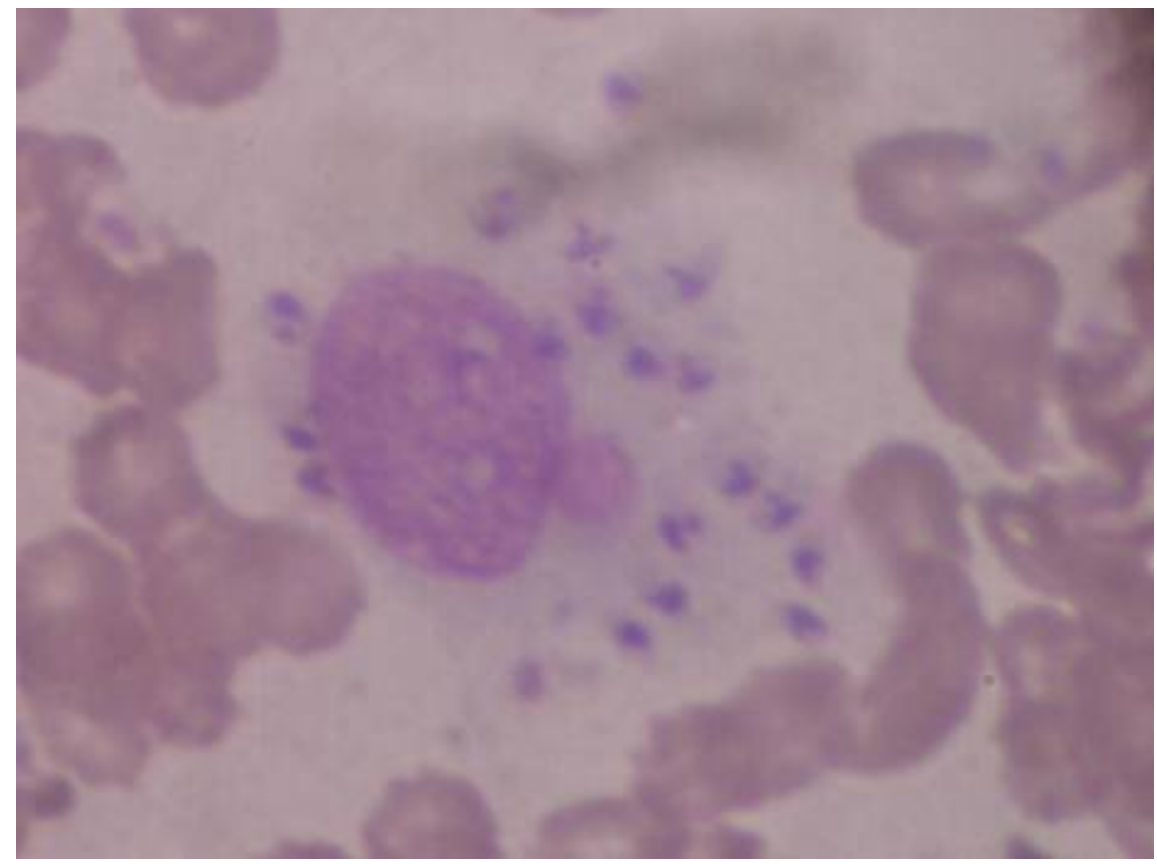

Figura 3. Amastigotas de Leishmania spp. em macrófago no baço de cão (Giemsa - 100x) 
FURTADO, M.V.L., VIOL, M.A. e BABO-TERRA, V.J. Pesquisa de amastigotas de Leishmania spp. em linfonodos, medula óssea, baço, pele e sangue de cães naturalmente infectados.

PUBVET, Londrina, V. 5, N. 30, Ed. 177, Art. 1198, 2011.

\section{Discussão}

Desde os anos 50, os cães vêm sendo alvo de ações governamentais para o controle da leishmaniose visceral, devido ao importante papel dessa espécie no ciclo de transmissão da doença. Desta forma, a detecção e eliminação de cães soropositivos têm se tornado uma prioridade em vários municípios brasileiros; entretanto, a eficácia deste procedimento vem sendo bastante questionada (Costa 2001).

Na década de 80, a LVC foi primariamente relatada na cidade de Corumbá-MS (Mello et al. 1988, Nunes et al. 1988) e nos últimos anos vem se expandindo para todo o estado. Desde então, métodos de diagnóstico vêm sendo aperfeiçoados com objetivo de identificar cães verdadeiramente positivos e negativos, para controle eficaz da doença sem que ocorra matança desnecessária destes animais.

O diagnóstico parasitológico é o método mais simples e mais utilizado nas clínicas veterinárias e a técnica, se realizada apropriadamente, é rápida e pouco traumática (Ferrer 1999). No presente estudo, a proporção de animais parasitologicamente positivos na punção de medula óssea foi de $50 \%$ para crista ilíaca e de 46,87\% para tíbio-femural, similar ao encontrado por Koutinas et al. (2001) e Ferrer et al. (1999), que foi de 50 a $83 \%$ para amostras colhidas desse órgão, independente da região colhida. Para amostras de linfonodos pré-escapular e poplíteo, encontramos 37,5\%, em comparação com 30 a $85 \%$ verificados pelos autores acima citados.

Em nosso estudo, não foi realizada a PCR para confirmar a espécie de Leishmania, nem a cultura das amostras obtidas para exames parasitológicos, o que seria fundamental para a confirmação dos casos nos quais não foram encontradas formas amastigotas no exame citológico. Também, não foi levada em consideração a presença ou não de sinais clínicos da doença, uma vez que foram utilizados animais destinados à eutanásia, devido ao exame sorológico positivo para leishmaniose, não sendo possível desta forma, a elaboração de 
FURTADO, M.V.L., VIOL, M.A. e BABO-TERRA, V.J. Pesquisa de amastigotas de Leishmania spp. em linfonodos, medula óssea, baço, pele e sangue de cães naturalmente infectados. PUBVET, Londrina, V. 5, N. 30, Ed. 177, Art. 1198, 2011.

correlações entre os achados parasitológicos, carga parasitária em diferentes órgãos e sintomatologia clínica.

Os testes sorológicos são importantes ferramentas no auxílio ao diagnóstico e estudo epidemiológico de diversas doenças. Estes testes proporcionam o diagnóstico indireto, uma vez que detectam a produção de anticorpos específicos contra um determinado antígeno. A reação de imunofluorescência indireta (RIFI), utilizada a partir da década de 60, demonstra sensibilidade que varia de 90 a $100 \%$ e especificidade aproximada de $80 \%$ para amostras de soro (Mohammed et al. 1986, Harth et al. 1987). A especificidade desse teste é prejudicada devido à presença de reações cruzadas com doenças causadas por outros tripanossomatídeos (Costa et al. 1991), levando a resultados falso positivos. Nesse estudo, foi observado que 4 animais sorologicamente positivos e parasitologicamente negativos para Leishmania spp. apresentaram mórulas sugestivas de Ehrlichia canis no material analisado levantando a possibilidade de reação cruzada entre estes parasitas ou a baixa carga parasitária de Leishmania spp., impossibilitando o achado de amastigotas nas amostras analisadas. Não podemos esquecer que o diagnóstico parasitológico é altamente específico, mas pouco sensível, permitindo falsos negativos. Porém, em regiões endêmicas para erliquiose e/ou babesiose, por exemplo, recomenda-se esgotar todas as possibilidades diagnósticas de infecções por estes e outros parasitas, por meio de repetidos exames sorológicos para Leishmania spp., além de avaliação parasitológica de medula óssea e linfonodos, a fim de evitar eutanásias desnecessárias.

Apesar dos problemas relatados, a RIFI é o método sorológico disponível que apresenta rapidez, facilidade de execução, adequada sensibilidade e especificidade e custo compensatório, possibilitando seu uso em associação com o diagnóstico parasitológico.

\section{Conclusões}

O diagnóstico definitivo de leishmaniose deve ser baseado na associação de resultados de testes sorológicos e moleculares e ainda, na detecção do 
FURTADO, M.V.L., VIOL, M.A. e BABO-TERRA, V.J. Pesquisa de amastigotas de Leishmania spp. em linfonodos, medula óssea, baço, pele e sangue de cães naturalmente infectados. PUBVET, Londrina, V. 5, N. 30, Ed. 177, Art. 1198, 2011.

parasita em esfregaços feitos a partir de amostras de medula óssea e linfonodos, que permitem o acesso mais fácil para colheita de material. 0 diagnóstico parasitológico é um método de simples execução, rápido e barato, que pode ser utilizado rotineiramente por médicos veterinários. No entanto, 0 estado imunológico do animal e a fase da doença podem interferir na carga parasitária, dificultando o achado das formas amastigotas.

\section{Agradecimentos}

Ao Centro de Controle de Zoonoses de Campo Grande por ceder os animais utilizados neste estudo e auxílio na coleta do material.

\section{Referências Bibliográficas}

ABRANCHES, P.; SILVA-PEREIRA, M. G. D.; CONCEIÇÃO-SILVA, F. M.; GOMES-SANTOS, G. M.; JANY, J. G. Canine leishmaniasis: pathological and ecological factors influencing transmission of infection. J. Parasitol. v. 77, p. 557-561, 1991.

BLAVIER, A.; KEROACK, S.; DENEROLLE, P.; GOY-THOLLOT, I.; CHABANNE, L.; CADORÉ, J. L.; BOURDOISEAU, G. Atypical Forms of Canine Leishmaniosis. Veterinary Journal v. 162, n. 2, p. 108-120, 2001.

BRASIL. Ministério da Saúde. Secretaria de Vigilância em Saúde. Departamento de Vigilância Epidemiológica. Manual de vigilância e controle da leishmaniose visceral. Editora MS, Brasília: Ministério da Saúde 120 pp. 2003.

CABRAL, M.; O'GRADI J. E.; ALEXANDER, J. Demonstration of Leishmania specific cell mediated and humoral immunity in assymptomatic dogs. Parasite Immunol. n.14 p. 531539, 1992.

CIARAMELLA, P.; OLIVA, G.; DE LUNA, R.; GRADONI, L.; AMBROSIO, R.; CORTESE, L.; SCALONE, A.; PERSESHINO, A. A retrospective clinical study of canine leishmaniasis in 150 dogs naturally infected by Leishmania infantum. Veterinary Record v. 141, n. 21, p. 539543, 1997.

COSTA, C. H. N. Mudanças no controle da leishmaniose visceral no Brasil. Informe Técnico. Rev. Soc. Bras. Med. Trop. v. 34, p. 223-228, 2001.

COSTA, C. A.; GENARO, O.; LANA, M.; MAGALHÃES, P.A.; DIAS, M.; MICHALICK, M. S. M.; MELO, M. N.; COSTA, R. Y.; MAGALHÃES-ROCHA, N. M.; MAYRINK, W. Leishmaniose visceral canina: avaliação da metodologia sorológica utilizada em inquéritos epidemiológicos. Revista da Sociedade Brasileira de Medicina Tropical v.24, n. 1, p. 21-25, 1991.

ENSERINK M. Infectious diseases. Has Leishmaniasis become endemic in the U.S.? Science v. 290 p. 1881-1883, 2000.

FEITOSA, M. M.; IKEDA, F. A.; LUVIZOTTO, M. C. R.; PERRI, S. H. V. Aspectos clínicos de cães com leishmaniose visceral no município de Araçatuba - São Paulo (Brasil). Clínica Veterinária n.28, p. 36-44, 2000.

FERRER, L. Canine Leishmaniosis: Evaluation of the Immunocompromised Patient. In: Wsava Congress Chooses, 8, 2002, Granada. Proceedings Disponível em: 
www.vin.com/proceedings/Proceedings.plx?CID =WSAVA2002\&PID=PR02653. Acesso em: $17 / 03 / 2004$.

FERRER, L. Leishmaniose. In: KIRK, R. W.; BONAGURA, J. D. Kirk's Current Veterinary Therapy XI Philadelphia: W. B. Saunders, 1992. p. 266-270.

FERRER, L. M. Clinical aspects of canine leishmaniasis. In: Canine Leishmaniasis: an update. Proceedings of the International Canine Leishmaniasis Forum. Barcelona Spain. Wiesbaden: Hoeschst Roussel Vet, p. 6-10, 1999.

FERRER, L.; AISA, M. J.; ROURA, X.; PORTÚS, M. Serological diagnosis and treatment of canine leishmaniasis. Veterinary Record v. 136, n. 20, p. 514-516, 1995.

FORTES, E. Parasitologia Veterinária. $3^{a}$ edição. Ícone editora. São Paulo. 1997. p.93-97.

GENARO, O. Leishmaniose visceral canina experimental. Belo Horizonte 1993. 202 p. Tese (doutorado) - Universidade Federal de Minas Gerais.

HARITH, A. E.; KOLK, A. H. J.; LAARMAN, J. J. Evaluation of a newly developed direct agglutination test (DAT) for serodiagnosis and sero-epidemiological studies of visceral leishmaniasis: comparison with IFAT and ELISA. Trans. R. Soc. Trop. Med. Hyg. v. 81, p. 603-606, 1987.

HERWALDT BL. Leishmaniasis. Lancet v. 354, p.1191-1199, 1999.

KONTOS, V. J.; KOUTINAS, A. F. Old World Canine Leishmaniasis. Compendium on Continuing Education Small Animal v. 15, n. 7, p. 949-959, 1993.

KOUTINAS, A. F.; POLIZOPOULOU, Z. S.; SARIDOMICHELAKIS, M. N.; ARGYRIADIS, D.; FYTIANOU, A.; PLEVRAKI, K. G. Clinical considerations on canine visceral leishmaniasis in Greece: a retrospective study of 158 cases (1989-1996). Journal of the American Animal Hospital Association v. 35, p. 376-383, 1999.

KOUTINAS, A. F.; SARIDOMICHELAKIS, M. N.; MYLONAKIS, M. E.; LEONTIDES, L.; POLIZOPOULOU, Z.; BILLINIS, C.; ARGYRIADIS, D.; DIAKOU, N.; PAPADOPOULOS, O. A randomised, blinded, placebo-controlled clinical trial with allopurinol in canine leishmaniosis. Veterinary Parasitology v. 98, n. 4, p. 247-261, 2001.

LEONTIDES, L. S.; SARIDOMICHELAKIS, M. N.; BILLINIS, C.; KONTOS, V.; KOUTINAS, A. F.; GALATOS, A. D.; MYLONAKIS, M. E. A cross-sectional study of Leishmania spp. infection in clinically healthy dogs with polymerase chain reaction and serology in Greece. Veterinary Parasitology v. 109, n. 1-2, p. 19-17, 2002.

MARZOCHI, M. C. A.; MARZOCHI, K. B. F. Tegumentary and visceral leishmaniasis in Brazil. Emerging anthropozoonosis and possibilities for their control. Cadernos de Saúde Pública v. 10, p. 359-375, 1994.

MELLO, D. A.; REGO Jr., F. A.; OSHIRO, E. T.; NUNES, V. L. B. Cerdocyon thous (L) (Carnívora, Canidae) Naturally Infected with Leishmania donovani chagasi (Cunha e Chagas, 1937) in Corumbá (Mato Grosso do Sul State, Brazil). Memórias do Instituto Oswaldo Cruz v. 83, n. 2, p. 259, 1988.

MOHAMMED, A. R.; WRIGHT, E. P.; ABDEL RAHMAN, A. M.; KOLK, A; LAARMAN, J. J.; PONDMAN, D. W. Seroadignosis of Saudanese visceral and mucosal leishmaniasis: comparision of ELISA-imunofluorescence and indirect haemagglutinarion. Trans. R. Soc. Trop. Méd. Hyg. v. 80 , p. $271-4,1986$.

NOLI, C. Leishmaniosis canina. Waltham Focus v. 9, n. 2, p. 108-120, 2001.

NUNES, V. L. B.; YAMAMOTO, Y. Y.; REGO Jr., F. A.; FORVAL, M. E. C.; GALATI, E. A. B.; OSHIRO, E. T.; RODRIGUES, M. Aspectos epidemiológicos da leishmaniose visceral em cães de Corumbá, Mato Grosso do Sul. Pesq. Vet. Bras. v. 8, n. 1/2, p.17-21, 1988. 
PASSOS, V. M. A.; FALCÃO, A. I.; MARZOCHI, M. C. A.; GONTIJO, C. M.; DIAS, E. S.; BARBOSA SANTOS, E. G. O.; GUERRA, H. L.; KATZ, N. Epidemiologycal aspects of american cutaneous leishmaniasis in a periurban area of the metropolitan region of Belo Horizonte, Minas Gerais, Brazil. Memórias do Instituto Oswaldo Cruz v. 88, n.1, p. 103-110, 1993.

PEARSON, R. D.; SOUSA, A. Q. Clinical sprectrum of leishmaniasis. Clinical Infectious Diseases v. 22, p.1-13, 1996.

QUINNEL, R. J.; CURTENAY, O.; DAVIDSON, S.; GARCEZ, L.; LAMBSON, B.; RAMOS, P.; SHAW, M. A.; DYE, C. Detection of Leishmania infantum by PCR, serology and celular immune response in a cohort study of Brazilian dogs. Parasitology v. 122, p. 253-261, 2001.

RIBEIRO, V. M. Leishmanioses. Revista do Conselho Federal de Medicina Veterinária n. 11 p. 13-14, 1997.

SANTA ROSA, I. C. A.; OLIVEIRA, I. C. S. Leishmaniose visceral: breve revisão sobre uma zoonose reemergente. ClínicaVeterinária n. 11, p. 24-28, 1997.

SCALONE, A.; DE LUNA, R,; OLIVA, G.; BALDI, L.; SATTA, G.; VESCO, G.; MIGNONE, W.; TURILLI, C.; MONDESIRE, R.; SIMPSON, D.; DONOGHUE, A. R.; FRANK, G. R.; GRANDONI, L. Evaluation of the Leishmania recombinant K39 antigen as a diagnostic marker for canine leishmaniasis and validation of a standardized enzyme-linked immunosorbent assay. Veterinary Parasitology v. 104, n. 4, p. 275-285, 2002.

SILVA, E. S.; GONTIJO, C. M.; PACHECO, R. S.; FIÚZA, V. O.; BRAZIL, R. P..Visceral leishmaniasis in the Metropolitan Region of Belo Horizonte, State of Minas Gerais, Brazil. Memórias do Instituto Oswaldo Cruz v. 96, p. 285-291, 2001.

SLAPPENDEL, R. J.; FERRER L. Leishmaniasis. In: Greene, C. E. Clinical Microbiology and Infectious Diseases of the Dog and Cat. $2^{\mathrm{a}}$ ed. Philadelphia: W. B. Saunders Co., 1990. p.450-458.

YAMAGUCHI, R. A.; FRENCH, T. W.; SIMPSON, C. F.; HARVEY, J. W. Leishmania donovani in the synovial fluid of a dog with visceral leishmaniasis. Journal of the American Animal Hospital Association v. 19, p. 723-726, 1983. 